\title{
The role of the chemical sciences training on the emission control systems in vehicles
}

\author{
Murat Cetin, Oguz Kursat Demirci \\ Vocational High School, Department of Automotive Tecnology, Erzincan University, Erzincan, Turkey
}

Email address:

mcetin@erzincan.edu.tr (M. Cetin)

To cite this article:

Murat Cetin, Oguz Kursat Demirci. The Role of the Chemical Sciences Training on the Emission Control Systems in Vehicles. Education Journal. Vol. 4, No. 1, 2015, pp. 20-26. doi: 10.11648/j.edu.20150401.15

\begin{abstract}
In industrial plants and motor vehicles basic environmental pollutants and trained human factors play a significant role for the reduction of pollution. This paper briefly describes the effect of chemical science, for the various stages used in the automotive technology training, in the Vocational Higher School in Turkish Higher Education System. The methodology used to improve the learning process in the associate degree level to undergraduate, for the automotive technology program unit emission systems course in the internal combustion engine emission laboratory. The aim of this automotive program is the design of products and process that maximize resource and energy efficiency, while minimizing waste, and thus reduces the environmental pollution. In the modern automotive technology, emission analyzers equipped with the skills to develop these sustainable technologies are particularly valuable. At the end of the training; automotive technicians perform laboratory and field tests to monitor environmental resources, and determine the contaminants and sources of environmental pollution. The best job opportunities exist for those with good diagnostic and problem-solving skills and who have been trained in basic electronics skills and new technology systems in the new vehicles.
\end{abstract}

Keywords: Chemistry, Training, Combustion, Emission, Vehicles

\section{Introduction}

Air pollution is one of the most important problems today and constitutes most of the environmental pollution. Atmospheric pollution is becoming more and more serious while the petroleum deposits on the earth are becoming lesser in number; these being the two serious problems that the world should face in 21st Century. According to the Environmental Protection Agency (EPA) data, $44 \%$ of hydrocarbon that lower the air quality in the atmosphere results from the transportation sector (Bata et al., 1994). The automotive manufacturers are responsible for ensuring that environmental regulations of all of the countries around the world should be met or exceeded. Governments throughout the world have recognized the need to limit the pollution generated by auto emissions; and the law mandates that vehicle manufacturers' products have to provide the specified emissions levels. Likewise, the periodic emissions measurements were made compulsory by governments in order to minimize the air pollution resulting from vehicles. The majority of the laboratories emitted different chemical compounds that are either hazardous themselves or poisonous because of the combustion reaction. The chemical sciences are important in the development of the systems that offer significant improvements to the fuel and exhaust systems in the vehicles (Karapantsios, 2008; Evans, 2008). In example; this situation has been demonstrated through the development of unleaded petrol (that eradicates harmful lead additives), detergent additives (that increase the fuel economy and engine lifetime), oxygenated fuels (that improve fuel efficiency), and catalytic converters (that reduce carbon monoxide, volatile organic compounds, and $\mathrm{NOx}$ emissions) (Bauer, 2004). Therefore, identifying the hazards of combustion process type and exhaust emissions should be performed in order to provide a safe workshop conditions for the workers/students. Trained human factors play an important role in the industrial plants and engines of vehicles for the reduction of basic environmental contamination and pollution (Cetin, 2006).

Human activities worldwide have been associated with a large amount of emissions of harmful species into the atmosphere. The emissions of $\mathrm{CO}_{2}, \mathrm{SO}_{2}, \mathrm{NO}_{\mathrm{x}}, \mathrm{VOC}, \mathrm{PM}$, and $\mathrm{N}_{2} \mathrm{O}$ is a great issue of concern. The researchers in different part of the world are engaged in the development of technologies for the control of these species emission. This 
research also indicates the importance of the control technologies for $\mathrm{CO}_{2}$ and NOx. On the other hand, applications generated in the vehicle emission systems to prevent different types of pollutions are also presented. The harmless $\mathrm{CO}_{2}$ and $\mathrm{H}_{2} \mathrm{O}$ come out after the completed combustion while inert $\mathrm{N}_{2}$ comes out exhaust pipe without a combustion reaction. Completed combustion is unfortunately not possible with the spark ignition engines because of engine configurations, wrong engine adjustments and engine sub systems (Bauer, 1996; Borat et al., 1996). As a result of uncompleted combustion, harmful emissions such as $\mathrm{CO}, \mathrm{HC}$, $\mathrm{NO}_{\mathrm{X}}$ and $\mathrm{PM}$ in high ratios come into atmosphere. $\mathrm{CO}$ is produced in a high degree by gasoline engines especially in idle speed; and the inhalation of air with a volumetric concentration of $0,3 \% \mathrm{CO}$ can result in death within 30 minutes. $\mathrm{HC}$, on the other hand, is formed as a result of uncompleted combustion or evaporated fuel from fuel tank. Some hydrocarbons are considered to be carcinogenic. When $\mathrm{NO}$ form $\mathrm{NO}_{2}$ which is a reddish brown, smelling and poisonous gas comes into air that causes a great effect on inhalation systems. Nitrogen is normally an inert gas that reacts at high compression ratio and high temperature and forms $\mathrm{NO}_{2}$ in the combustion process (Bauer, 2004; Klingebiel et al., 2005).

Turkey is located between Europe and Asia; this geographic situation gives the Turkish automotive industry an important strategic advantage. Italy, Germany, France, Japan, USA, and North Korean automotive companies have significant investments in Turkey since the production costs are lower in Turkey compared to the developed EC countries. Today, there are 19 companies in production, of which 5 are automobile producers and 14 are commercial vehicle producers, in Turkey. Most of the companies in this sector have foreign partners and produce for domestic and international markets. The automotive industry is among the 4 largest exporters as one of the leading investor industries of the Turkish economy. It is an economically strategic sector in terms of its significant contribution to the national production and development, direct and indirect employment, and level of technology in Turkey. It provides employment for more than 500,000 people, with related sub sectors, and attracts foreign investors. Therefore, the quality of the automotive sector employee and training is very significant (Society of Turkish Automotive Industry, 2009).

\section{Overview of the Training in the Automotive Sector and Careers of Automotive Technicians in Turkey}

The automotive program graduates work in the vehicle production plants and vehicle maintenance sectors, and the majority of the graduates also find employment in a wide range of industries. Consequently, the vocational schools in the automotive technology program should place more emphasis on developing students' transferable skills. On the other hand, automotive technology is continuously becoming more and more complex. The experts recommend that the applicants should first obtain formal training through high school or a vocational higher school in Turkey. Some workers in the sector, on the other hand, are learning their profession by working along with more experienced workers for a long time. Automotive technician training programs are offered by factory schools, vocational high schools, community colleges, and vocational schools. In vocational higher school programs the concept of car repair is thought more thoroughly to the student. Conventionally, an automotive service technician is employed in a garage and serves between 3-5 years as an apprentice before becoming a service technician. Vocational higher training programs are nowadays becoming more popular whereas apprenticeships are less common in Turkey. Vocational higher schools training program has a 2 semester typically in a year, in a total of 2 years, set by the Turkish Higher Education System. Vocational courses and core courses like English, mathematics, physics, chemistry, computer education, which lead students to achieving an associate degree or certificate, are included in the program. Some vocational higher schools could add specific courses to improve the skills of the students. Furthermore, there is a variety in content of the courses in the programs between the vocational higher schools because of different regional developments (Turkish Industrialists' and Businessmen's Association, 2001).

The automotive program has two sub-branches named aftermarket and production programs. Therefore, the automotive program trains for 2 sub-branches. Some students are trained to work in the after-sales while the other group students are trained to work in the vehicle production plant. Most of the students are trained to receive their technician's certification, so that they can work in the service, while some programs merely introduce the student to the industry and give them a better understanding of automotive technology suitable for a consumer. Sufficient vital skills are thought more in the profession in order to help the student landing a job as a helper to a mechanic- a trainee, or a car plant worker. The first groups of students are trained to for work in sales while the other group students are trained to work in the vehicle production plant. Many automobile manufacturers have training programs available through 2-year associate degree schools and they accredit to many automobile technology schools in Turkey (The Turkish Council of Higher Education, 2002).

In the national education policy; the curriculum of these schools is updated to keep pace with the advancements in technology and changes in equipment. Students have to attend the course programs in the alternate 14 week periods per semester. At the end of the two semesters, students have to work full time as an internships working in repair shops or dealerships for 8 weeks. In these repair shops or dealerships, students provide great hands-on-experience with the supervision and aid of an experienced repairer who provides instruction and tips to the student. All of the higher schools, postsecondary schools, technical schools, and community colleges can provide automotive service training that is 
followed by the certification program; which sets the national standard. Training note, equipment, and new vehicles are provided from different manufacturers by the schools so that students improve their skills and gain experience with the latest models of vehicles. The graduated student with good communication and analytical skills are sought, in the automotive service technician positions, by employers. The schooling of a service technician involves repair of automotive sub systems, electronics, physics, chemistry, English, computers, and mathematics (The Turkish Council of Higher Education, 2002).

Training programs additionally increase the trend of using computer process modeling and reduce pilot plant studies in education and industry. Important instruments and hand tools are used by technicians in repair shops or dealerships. The expensive test tools, such as power tools, engine analyzers, emissions analyzers, and diagnostic tools, are provided by the employers. Many entry-level technicians are able to acquire tools thanks to arrangements between the tool manufacturers and training programs. Automotive service technicians, after graduation, typically have the opportunity to attend manufacturer training centers, thanks to their employers, where they are taught how to repair new models and components, like air conditioning units or fuel injection systems. Employees are sent to training programs to increase their skills; and thus make them more valuable to the employer. Factory representatives might also come to individual repair shops to carry out brief training sessions for the mechanics and technicians. Technicians gain experiences over time and become the office managers or foremen, or the service manager or supervisor in repair shops of dealership and car factory. Technicians who interact positively with customers might become automotive repair service trouble estimator, and some of them may open their own service or workplace(Young et al., 2006).

The graduated student who finishes automotive training programs in higher schools, vocational and technical schools, or community colleges is likely to have good job opportunities in automotive industry. The work of automotive service today has evolved from mechanical repair to a high technology job. Thus, these workers are usually called "technicians" in automotive service sectors. Technicians must have a base of knowledge about how vehicles' complex components work and interact; as well as the ability to work with electronic diagnostic equipment and computer-based technical reference materials. Computers also have become common in the modern repair shops. Service technicians compare the readouts from computerized diagnostic testing devices with the benchmarked standards given by the manufacturer. Tune-up technicians adjust the ignition timing and valves, and adjust or replace spark plugs and other parts to ensure efficient engine performance. They often use electronic testing equipment to isolate and adjust malfunctions for fuel, ignition, and emissions in the control systems. Excellent reasoning skills and an understanding of vehicles are necessary for a technician to rapidly and precisely identify the problem. If one receives good training and thus has an excellent technical foundation, a career in automotive service presents a great chance for good wages and high satisfaction associated with doing complicated work on vehicles by using advanced technology. Besides new positions caused by growth within the industry, positions will be available as result of workers transferring to different jobs. Diagnosing illusive problems proves to be challenging for technicians but also provides a great deal of satisfaction. A vehicle presently uses high-tech computers and complex electronic systems to monitor the performance. Significant occupation factors about training programs related occupations are summarized below:

- The ideal preparation for technology intense jobs is formal automotive technician training.

- Those with a working knowledge of electronics, chemistry, and mathematics, as well as excellent problem-solving abilities will have good opportunities for employment.

- Advancements in the technology cause automotive service technicians and mechanics to be continuously learning and improving new methods of repair.

\section{Courses, Methods of Training of Basic Chemical Combustion in the Automotive Program}

Chemical combustion courses have been thought the first and third semester in the two years. The main objectives of automotive technology training are the foundation of combustion theory that mainly deals with the combustion phenomena for the power equipment. In this course, chemical thermodynamics and combustion physical chemistry in combustion process are described in detail and the ignition, flame propagation, and combustion product compositions of the liquid, solid, and gaseous fuel, respectively, are also mentioned. This instructional course utilizes consumer product information and lets the students compare the theoretical stoichiometric calculations of the air fuel ratio, car emissions, and fuel consumption data. Representing the rich or lean mixture versus consumption of fuel graphically provides a tangible way of connecting concepts studied in the emission course classes to everyday life issues. The considerable simplification of an otherwise complex chemistry problem provides comparable theoretical and practical actual data. Training of practice skills activity is also used by the students to perform emission measurements in the emission laboratory. This training activity may be used to bring awareness of significant issues related to car emissions; such as the environmental impacts of different emissions and the differences of hybrid engines or gasoline versus diesel engines. Scientific literacy approached by performing experiments and practical activities in workshops classroom. Combustion theory foundation is a major professional basic course for the students majored internal combustion engines, thermal engineering, and environmental engineering. The objective is to ensure that students have 
basic understanding for the combustion phenomena and basic theory so that they will have the basic knowledge about the theories of thermo chemistries, combustion kinetics and combustion after these courses. The students are required to comprehend the fuel and combustion characteristic of the gaseous, liquid, and solid fuel used in power and mechanical engineering, as well as the form and condition of ignition, the flame propagation, and the mechanism for the productions formation. Through the studying of this course, students would have an overall view on combustion phenomena and the internal combustion engines. It will also be useful for the next generation as regards to improving the combustion equipments, raising the energy utilization ratio, analyzing the mechanism and formation of harmful emission, preventing abnormal combustion phenomena, and controlling and reducing harmful emissions.

\section{Emission Training Course Contents and Chapter Details}

The Automotive technology program was designed in terms of the learning outcomes and competences to be acquired; the total student workload to meet the objectives of the program was estimated; and the entire course was programmed and planned in a detailed schedule. A course guide was elaborated including all this information; thus, resulting in a useful instrument for teachers and students. This methodology has been applied to for Automotive technician degree that is thought for four semesters in two 2 years. Table 1 displays the categories of automotive program courses, credits, and ECTS values for 4 semesters.

Emissions related to content are examined according to the distribution of the courses in the semesters. For example some basic knowledge about air and chemical composition, combustion and types of combustion are presented as a theory in the third chapter of Physics (Principles of Technology) course belonging to the first semester. The Occupational Safety Course, on the other hand, describes harmful chemicals, chemical effects of emissions, and the related warning signs are learned. The aim is the investigation of more effective teaching methods to improve the awareness as regards to the labeling and safe handling of chemical substances.

There are two main courses in the first semester: Engine Thermodynamics and Engines Technology courses. As regards to the chemicals in the Engine Thermodynamic course, basic thermodynamic concept and equations, work and heat, thermodynamic laws, cycles, efficiency, combustion and reactions, and combustion of hydrocarbons complicated dissociations are explained in the chapters of the course. When the chemical processes in the Spark Ignition Engine Fuel and Ignition Systems course are considered, combustion and combustion process, chemical form of gasoline, mixtures formation and ideal fuel/air ratio, combustion chamber, fuel system and carburetors, and fuel injection system are explained in the chapters.In the second semester, the chemical properties of diesel fuels, combustion of diesel engine and diesel emissions are explained in different chapters of Diesel Engines And Fuel Injection Systems course.

Table 1. Automotive Program courses categories, credits, and ECTS.(Te= Teorical, Ap = Aplicational, Ho=Hour, C=Compulsory, $V=$ Vocational , E=Elective, $R=$ Required,)

\begin{tabular}{|c|c|c|c|c|c|c|}
\hline \multicolumn{2}{|c|}{ Course Title } & Teori & Ap & Hours & $\mathrm{C} / \mathrm{C} / \mathbf{E}$ & ECTS \\
\hline \multirow{6}{*}{ 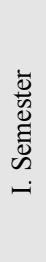 } & Physics & 3 & 0 & 3 & $\mathrm{C}$ & 3 \\
\hline & Automotive Electricity & 3 & 1 & 4 & $\mathrm{C}$ & 5 \\
\hline & Engines Technology & 2 & 2 & 4 & $\mathrm{C}$ & 4 \\
\hline & Engine Thermodynamics & 3 & 0 & 3 & $\mathrm{C}$ & 2 \\
\hline & Occupational Safety and Occupational Health & 2 & 0 & 2 & $\mathrm{E}$ & 2 \\
\hline & Turkish Language II & 2 & 0 & 2 & $\mathrm{C}$ & 2 \\
\hline \multirow{4}{*}{ 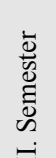 } & Diesel Engines And Fuel Injection Systems & 2 & 2 & 4 & $\mathrm{C}$ & 4 \\
\hline & Automotive Electronics & 3 & 1 & 4 & $\mathrm{C}$ & 3 \\
\hline & Technical Drawing & 2 & 1 & 3 & $\mathrm{C}$ & 3 \\
\hline & Material Technology & 2 & 0 & 2 & $\mathrm{C}$ & 2 \\
\hline \multirow{3}{*}{ 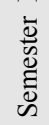 } & Vehicle Motion Control Systems & 3 & 1 & 4 & $\mathrm{C}$ & 4 \\
\hline & Engine Testing and Servicing & 2 & 2 & 4 & $\mathrm{C}$ & 4 \\
\hline & Emission Control Systems & 1 & 1 & 2 & $\mathrm{E}$ & 3 \\
\hline \multirow{2}{*}{$\Xi$} & Alternative Engines and Fuels Systems & 3 & 1 & 4 & $\mathrm{C}$ & 4 \\
\hline & Comfort Systems & 3 & 1 & 4 & $\mathrm{C}$ & 4 \\
\hline \multirow{4}{*}{ 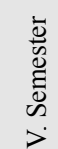 } & Mechanics Of Motor Vehicles & 3 & 1 & 4 & $\mathrm{C}$ & 4 \\
\hline & Heating And Cooling Systems & 1 & 1 & 2 & $\mathrm{E}$ & 2 \\
\hline & Environmental Protection & 2 & 0 & 2 & $\mathrm{E}$ & 2 \\
\hline & INTERNSHIP(The 30 working days during the summer break) & & & & $\mathrm{R}$ & 8 \\
\hline \multicolumn{2}{|c|}{ TOTAL } & & & & & 73 \\
\hline
\end{tabular}

In the third semester, Engine Testing and Tune Up course 
torque and specific fuel consumption, energy balance in engine, engine efficiency, engine and fuel system tests, and exhaust emissions tests. The Emission Systems course, in the third semester, explains the use of chemical processes and contains the evaluation of chemical information about the emissions; and thus concludes important lessons. This course has the objectives as summarized below and Table 2 displays the categories Emission Systems course and related issues in its chapters.

1. Recognizing the pollutants emitted around the vehicles, the source of these pollutants vehicles systems will help vehicle technology to increase the environmental sensitivity of the students.

2. Describing all kinds of elements in the foreground of the environmental studies and clean environment concept but keeping in mind this may only be possible with the advanced technology and trained technical staff to make the grip.

Description of this course was especially taken as an example since courses in the classroom are implemented by using extensive visual techniques and they are generally both theoretical and practical courses. Laboratory emission reduction systems on the existing engines and making adjustments on the measurement are described. Otto and diesel engine vehicles exhaust emissions is shown as a practical measure for situations such as being in traffic. The concept of the vehicles used in emission control systems includes the recent developments in the process; and the students' comprehension of environmental standards on source pollutants in vehicles is possible. This course consists of $70 \%$ theoretical work in the classroom and $30 \%$ practical experiments in the laboratory. The percentage of the concepts in the chapters of the Emission Systems can be seen in Table 2. The midterm exams and the final exam of the course are taken into account for calculating this percentage. The objectives of the emission control systems can be stated briefly as follows;

Describing the fuels used in the types, characteristics, forms a mixture of air, a mixture of the heat value, and combustion type of combustion event to understand what kind and what type of pollutants should added for the calculation of the generated gas; and to comprehend the significance of the impact of the pollutant emissions from vehicles on the human health and atmosphere. The structural features (compression, combustion chamber shape, absorption manifold format, valve timing, etc.) and setting values (air/fuel ratio, spark plug electrode spacing, platinum range, ignition advance, injection advance, and will be sprayed with a stroke amount of fuel etc.) of the gasoline and diesel engines also have a considerable impact on emissions. The engine operating conditions and load transfer of the entire vehicle speed corresponding to the disclosure of the magnitude cause emissions; these values, however need to be adjusted for making the calculation possible. Fuel from the fuel tank to engine and exhaust system should be worked on, for understanding the logic, and the necessary maintenance and checks should be performed, until the system can recognize, to reduce emissions coming from the atmosphere. Gasoline and diesel vehicles should be tested; and the measurement methods and standards should be known and applied.

Table 2. Emission Systems course and related issues in its chapters

\begin{tabular}{ll}
\hline ISSUES & Area in chapters(\%) \\
\hline A. Fuels, combustion and combustion reactions & 20 \\
B. Vehicles and air pollution effects on sources of pollutants & 05 \\
C. Engine construction features, setup and maintenance of the value impact on emissions & 20 \\
D. Different effect on emissions of vehicles working conditions & 05 \\
E. Vehicles sourced pollutants taken preventive measures & 25 \\
F. Statutory limitations and emissions for pollutants measurement techniques & 25 \\
\hline
\end{tabular}

The course objectives can be summarized as follows;

1. General information related to the liquids (gasoline diesel) and gas (NG, LPG, hydrogen) fuel will be learned.

2. Basic concepts related to combustion and combustion types (theoretical full combustion, incomplete combustion and incomplete combustion partial) will be comprehended. All types of fuel combustion products formed and the pollutant emissions will be calculated.

3. The impact of exhaust gas pollutants on health and environment will be learned.

4. Pollutants described for the measurement units, (ppm, $\mathrm{mg} / \mathrm{m}^{3}, \%$ ) will be grasped.

5. The students will know the concepts of combustion chamber shape, surface/volume ratio, and compression ratio.

6. The effects of intake manifold shape, valve timing, ignition system (spark plugs number, location and types) on the emissions will be comprehended.

7. The students will learn the effects of fuel injection method, over filling, the air / fuel ratio, ignition advance, and fuel emissions.

8. The conditions of warming, no-load, speed cutting, constant speed, and acceleration, according to the size of atmospheric gases and pollutants spread, in vehicles will be comprehended.

9. The students will know the work principles of gasoline engines for positive crankcase ventilation system, fuel tank ventilation systems, and exhaust gas back fire movement; which are widely used in the thermal reactors and catalytic converters.

10. For diesel engines, the techniques for electronically controlled injection system and the work of over-filling and particle filter will be grasped by students. 
11. The students will know how to do which type of test for new vehicles.

12. The students will learn how to make the emission measurements for gasoline and diesel vehicles.

13. The legal regulations regarding the emission limit values will be comprehended.

The Alternative engines and fuels course in the fourth semester, as regard to chemicals explains the concepts of alternative engines and fuel, compressed natural gas, liquid hydrogen fuel, liquid petroleum gas, vegetable oils and biodiesels, fuel cells, and alcohol fuels. Experimenting with one or more of the following topics is desired in the course: engine dynamometer testing, engine controls, petrol or diesel engine testing, combustion analysis, engine modeling, catalyst testing and evaluation, emissions measurement with conventional gas analyzers, particulate measurement, exhaust speciation with gas analysis and mass spectrometry, and data acquisition systems.

This approach, adopted in the automotive technician education program, represents a change from standard training laboratory practiced, as regards to chemical combustion instruction, using concepts that fit with the environmentalist approach of vehicle pollution, engine performance, and fuel economy evaluation. This approach was implemented by either the manufacturer sector or the demand of the auto service employers-owners requesting the aid of mentoring from instructors via lectures about targeted review. New educational program show that performing chemical theoretical training and practical emission applications on the vehicles dramatically increased the students' level of learning. This newer comprehension was becoming more evident with the better student performance in the assessment tasks such as the new technology laboratory proposal, participation and reports. After graduation; student feedback from 3-5 years of this implementation that applies the new experimental design approach to automotive technician education program, which is generally regarded as effective, useful, and applicable. The new educational program learning has an innovative and reformist approach as regards to the chemical combustion teaching in the emission control system. Furthermore, it is considered as a much better approach than the traditional approach of founding automotive laboratories for the emission training courses.

The total student's workload was reduced also with this new program. Thus, an additional time is provided to the student for implementing new methodologies that is required to acquire general and transferable skills. The credits gained from Automotive Technology Program courses are useful for reducing the theoretical contents, adjusting the student workload for every subject to its available ECTS, and taking into account the capacity of a "reference student" into account since trainer workload, of the new technologies, is significantly increased. The new developments in technology and new test devices that are continuously iterative must be controlled by evaluations. Likewise, a great number of materials elaborated for the students must be checked in order to follow its continuous evaluation. Moreover, as an additional coordination and planning tasks in reverse time should be applied. The ratio student/teacher workload must be increased in order to reduce the teacher workload. The application of the new methodology was satisfactory and the main objectives proposed at the beginning of the experience were reached although some aspects should be improved. The main objectives as regards to the use of new learning strategies and helping the students to get some general and transferable skills has been attained; and the new methodology will be implemented with better employment figures since the expectation of the Automotive technician degree has been adapted in the sector.

\section{Results}

There is an ongoing effort at universities in Turkey to integrate the abovementioned new tools and ideas for the improvement in the internal combustion engines emissions. The effect of the chemical science courses on emission training and analysis examples presented in the automotive program of sustainability was investigated in this study. The emission courses and laboratories are valuable because they illustrate that many of the same concepts have different types exhaust emissions for clean air requirements with experiments. Students can use a real time test car and gas analyzer to investigate the cause-effect relationships, such as the effect of temperature, pressure, or ignition time and different fuel and fuel blends, and initial emission concentrations on tail pipe, in the combustion process. Before using real models for experimental learning, it is required that the students should have some tactile experience with the equipment and the process. The experimental model that uses real vehicles is utilized for the learning process; and gaining practical experience with the equipment and training process is provided for the students. New technologies in the emission search for the possibility of optimizing the situation by minimizing local pollution levels and at the same time being mindful of the global impact. Training courses presents the students the opportunity to define the vehicle emission and its own problems through making assumptions, deciding upon what is to be included or excluded in the environment, and estimating values for the emission emitted to atmosphere. On the other hand, it can be seen that there is a variation in the performance of students according to the different learning styles implemented that need to be addressed as well.

- Although the integration of safety with automotive technician education is important, it has not been sufficiently wide spread in the workplace. There appears to be developments at least in the short term to its full integration. Nonetheless, developing notable efforts for an extensive integration may be the next challenge in the Turkish Automotive Industry.

- Automotive industry acts in the global market, and therefore, it is imperative that the students should be prepared to work everywhere in the world where their experience is needed. The same difficulties for teaching 
classical safety in vehicle emissions raise the risk factors raise for healthy environments as well.

- The best job opportunities exist for those with good diagnostic and problem-solving skills and trained in basic electronics skills regarding the new technology systems for new vehicles. A lot of competition for beginner jobs should be expected if the graduated person has a formal automotive training.

- The students can also conduct researches on advanced internal combustion engines emissions control technologies and advanced engine combustion in the training period. Although a background in knowledge of internal combustion engines emissions related to the mechanical engineering, chemical engineering, or chemistry and their sub systems are preferred other disciplines might also be considered.

- After training, significant results could come from determining the specific chemical species in engine emissions that cause the health effects.

- This learning methodology provides the students with an integrated and applied vision of different fuel main chemical combustion subjects (environmental technology).

- Students learn a general chemistry knowledge and information about the increase in emission control systems within four semesters; and significant improvements in their capabilities are observed (team work, new vehicles and new emission systems, information search, measurement and analysis, decision making, written reports, oral presentations, etc.) that are difficult to develop with traditional learning methodology.

- The continuous learning process evaluation with lifelong learning will contribute to the big transition of feedback information in order to get an improvement in the continuous methodology.

- The vocational courses that include teaching and work planning (theoretical and practical classes, seminars, vehicle practices, laboratory works, team works, tutorial sessions, technical visits, conferences, etc.) has become an essential tool in the end to coordinate the new learning strategies developed.

\section{References}

[1] Bata, R.M., Jett, B.T., Reale, M.J., 1994, Alternative fuels in $\mathrm{CI}$ and heavy duty engines, Society of Automotive Engineers Inc. USA.

[2] Bauer, H.,2004, Gasoline engine management. Robert Bocsh $\mathrm{GmbH}$, Stuttgart.

[3] Bauer, H., 1996, Automotive handbook, Robert Bocsh GmbH, Stuttgart.

[4] Borat, O., Sürmen, A., Balcı. M., 1996, Air Pollution and control techniques. Ankara.

[5] Cetin, M., 2006, Educated mechanic, clean vehicle and clean environment. EU Project, Regions-Local Development, Erzincan.

[6] Evans, G.M., Galvin, K.P., Doroodchi, E., 2008, Introducing quantitative life cycle analysis into the chemical engineering curriculum. Education for chemical engineers, 3: 57-65.

[7] Karapantsios, T.D., Boutskou, E.I., Touliopoulou, Mavros, E. P., 2008, Evaluation of chemical laboratory safety based on student comprehension of chemicals labelling. Education for chemical engineers, 3:66-73.

[8] Klingebiel M., Dietsche, K.H., Müller. R., 2005, Emission control technology for diesel engines. Robert Bocsh $\mathrm{GmbH}$, Stuttgart.

[9] Society of Turkish Automotive Industry., 2009, The Turkish automotive industry reports. Ankara.

[10] Turkısh Industrialists' and Businessmen's Association, 2001, Restructuring of the vocational and technical education system in Turkey.

[11] The Turkish Council of Higher Education, 2002, Curriculum development project. Automotive program book.

[12] Young, B.R., Yarranton, H.W., Bellenhumeur, C.T., Svrcek, W.Y., 2006, An experimental design approach to chemical engineering unit operations laboratories. Education for chemical engineers 1:16-22. 